\title{
Polymer composites with cork particles functionalized by surface polymerization for fused deposition modelling
}

\section{SUPPORTING INFORMATION}

\author{
Alberto S. de León*, Fernando Núñez-Gálvez, Daniel Moreno-Sánchez, \\ Natalia Fernández-Delgado, Sergio I. Molina
}

Dpto. Ciencia de los Materiales, I. M. y Q. I., IMEYMAT, Facultad de Ciencias, Universidad de Cádiz, Campus Río San Pedro, s/n, 11510 Puerto Real (Cádiz), Spain.

*corresponding author: alberto.sanzdeleon@uca.es

Keywords: cork, composites, additive manufacturing, fused deposition modelling, surface modification, circular economy, renewable resources. 


\section{Calculation of the hydroxyl number (OHN) of the cork particles}

The procedure to obtain the $\mathrm{OHN}$ of the cork particles (i.e. the amount of $-\mathrm{OH}$ groups available for reaction) is adapted from ASTM D1857 as follows:

First, the acetic anhydride $\left(\mathrm{CH}_{3} \mathrm{CO}\right)_{2} \mathrm{O}$ reacts with the hydroxyl groups of the cork particles $\mathrm{R}-\mathrm{OH}$ producing the acetylation of the cork particles and acetic acid $\mathrm{CH}_{3} \mathrm{COOH}$ as shown in reaction (1):

$$
\mathrm{R}-\mathrm{OH}+\left(\mathrm{CH}_{3} \mathrm{CO}\right)_{2} \mathrm{O} \rightarrow \mathrm{R}-\mathrm{OOC}-\mathrm{CH}_{3}+\mathrm{CH}_{3} \mathrm{COOH}
$$

In these conditions, it can be ensured that all the $\mathrm{R}-\mathrm{OH}$ moieties of the cork particles will be acetylated, since $\left(\mathrm{CH}_{3} \mathrm{CO}\right)_{2} \mathrm{O}$ is in excess and therefore the amount of acetylated groups is equivalent to the $\mathrm{OHN}$. Then, the excess of $\left(\mathrm{CH}_{3} \mathrm{CO}\right)_{2} \mathrm{O}$ is hydrolyzed with $\mathrm{H}_{2} \mathrm{O}$ according to reaction (2):

$$
\left(\mathrm{CH}_{3} \mathrm{CO}\right)_{2} \mathrm{O}+\mathrm{H}_{2} \mathrm{O} \rightarrow 2 \mathrm{CH}_{3} \mathrm{COOH}
$$

Finally, all the acetic acid $\mathrm{CH}_{3} \mathrm{COOH}$ produced in (1) and (2) is titrated with a $0.5 \mathrm{M}$ $\mathrm{NaOH}$ solution, as indicated in reaction (3):

$$
\mathrm{CH}_{3} \mathrm{COOH}+\mathrm{NaOH} \rightarrow \mathrm{CH}_{3} \mathrm{COONa}+\mathrm{H}_{2} \mathrm{O}
$$

In the control experiment (i.e. in absence of cork), (1) does not take place, therefore all the $\mathrm{CH}_{3} \mathrm{COOH}$ is produced according to (2). Reaction (1) produces 1 mol $\mathrm{CH}_{3} \mathrm{COOH} /\left(\mathrm{CH}_{3} \mathrm{CO}\right)_{2} \mathrm{O}$ while reaction (2) produces $2 \mathrm{~mol} \mathrm{CH}_{3} \mathrm{COOH} /\left(\mathrm{CH}_{3} \mathrm{CO}\right)_{2} \mathrm{O}$. The $\mathrm{OHN}$ is proportional to $\mathrm{CH}_{3} \mathrm{COOH}$ produced in (1), therefore to the difference between the $\mathrm{NaOH}$ needed after (1) and (2) in presence of cork $V_{\mathrm{NaOH}, \mathrm{cork}}(\mathrm{mL})$ and the control $V_{\mathrm{NaOH}, \mathrm{control}}$. Precisely, the OHN can be calculated as:

$$
\frac{m m o l-O H}{g_{\text {cork }}}=\frac{\left(V_{N a O H, \text { control }}(m L)-V_{N a O H, c o r k}(m L)\right) \cdot 0.5 \mathrm{mmol} \mathrm{NaOH} / \mathrm{mL}}{m_{\text {cork }}(g)}
$$

The experimental results for the three repeats done are presented in Table S1. 
Table S1. Amount of cork used ( $\left.\mathrm{m}_{\mathrm{cork}}\right), \mathrm{NaOH}$ volume needed for titration after (1) and (2) in presence of cork $\left(\mathrm{V}_{\mathrm{NaOH} \text {,cork }}\right), \mathrm{NaOH}$ volume needed for the control $\left(\mathrm{V}_{\mathrm{NaOH} \text {,control }}\right)$ and $\mathrm{OHN}\left(\mathrm{mmol}-\mathrm{OH} / \mathrm{g}_{\text {cork }}\right)$ for each repeat.

$\begin{array}{ccccc}\text { \#repeat } & \begin{array}{c}\mathbf{m}_{\text {cork }} \\ \mathbf{g})\end{array} & \begin{array}{c}\mathbf{V}_{\mathbf{N a O H}, \mathbf{c o r k}} \\ \mathbf{( m L )}\end{array} & \begin{array}{c}\mathbf{V}_{\mathbf{N a O H}, \text { control }} \\ (\mathbf{m L})\end{array} & \begin{array}{c}\text { OHN } \\ \left(\mathbf{m m o l}-\mathbf{O H} / \mathbf{g}_{\text {cork }}\right)\end{array} \\ 1 & 0.3325 & 9.7 & 10.0 & 0.451 \\ 2 & 0.3327 & 8.4 & 9.2 & 1.202 \\ 3 & 0.3366 & 8.3 & 8.8 & 0.742\end{array}$




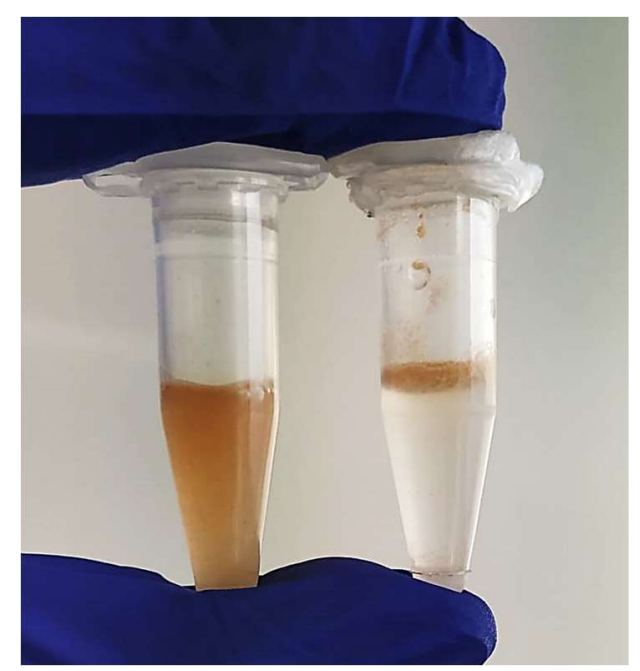

Figure S1. Eppendorf tubes containing aqueous solutions of approximately $5 \mathrm{mg} / \mathrm{mL}$ of $\mathrm{C}$ (left) and $\mathrm{C}_{\mathrm{m}}$ (right), seconds after being shaken vigorously. It can be observed that $\mathrm{C}$ particles remain dispersed in water, while $C_{m}$ rapidly float towards the surface due to their highly hydrophobic behavior. 


\section{Correlation of the experimental mechanical properties with rule of mixtures}

The rule of mixtures states that the upper and lower bounds for the Young's modulus of a composite made of a polymeric matrix and equiaxed particles can be estimated as:

$$
\begin{aligned}
& E_{c}(\text { upper })=E_{m} y_{m}+E_{p} y_{p} \\
& E_{c}(\text { lower })=\frac{E_{m} E_{p}}{y_{m} E_{p}+y_{p} E_{m}}
\end{aligned}
$$

Where $E$ is the Young's modulus, $y$ the volume fraction and sub-indexes $c, m$ and $p$ represent the composite, matrix (ASA) and particles (cork), respectively.

Taking as a reference $\mathrm{E}_{\mathrm{m}}=1700 \mathrm{MPa}$ (from experimental tensile testing of 3D printed pure ASA specimens, see Table 2) and $\mathrm{E}_{\mathrm{p}}=31.5 \mathrm{MPa}^{1}$, the graph for the rule of mixtures of the Young's modulus of the system ASA + cork is shown in Figure S2. In this figure there are also included the experimental values dissected from the tensile testing curves of $\mathrm{ASA}+\mathrm{C}$ and $\mathrm{ASA}+\mathrm{Cm}$. It must be noted that the volume content for these composites containing $5 \mathrm{wt} \%$ cork corresponds to $22.5 \mathrm{vol} \%$ due to the low density of cork (200 $\mathrm{kg} / \mathrm{m}^{3}$ ). The graph clearly shows how the composites containing $C_{m}$ increase the Young's modulus up to practically the upper limit of the theoretical calculations, evidencing that the surface polymerization of cork with PBA greatly enhances the compatibility between the particles and the ASA matrix. 


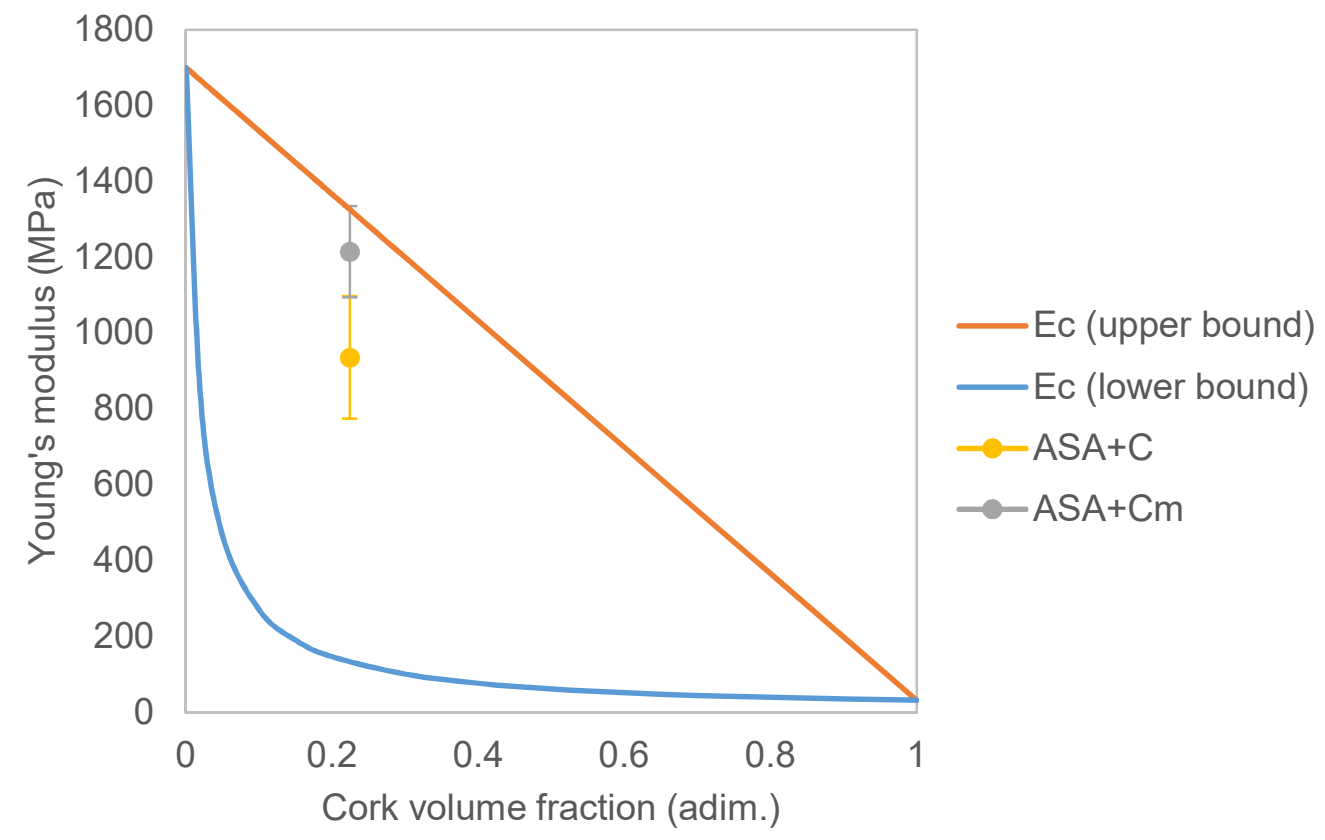

Figure S2. Predicted upper (orange line) and lower (blue line) bounds of ASA + cork composites according to the rule of mixtures. The experimental values obtained for the Young's modulus of $\mathrm{ASA}+\mathrm{C}$ and $\mathrm{ASA}+\mathrm{Cm}$ are presented in yellow and grey respectively.

(1) Ansys Granta EduPack software, ANSYS, Inc., Cambridge, UK, 2019. 
Table S2. Density values of $\mathrm{ASA}, \mathrm{ASA}+\mathrm{C}$ and $\mathrm{ASA}+\mathrm{C}_{\mathrm{m}}$, calculated theoretically from the values provided by the suppliers and measured experimentally from the filaments and 3D-printed objects. Experimental values of the extruded filament are in well-agreement with the theoretical ones, indicating that the filament was successfully printed, without significant porosity or densification of the cork particles. Experimental values for the 3Dprinted objects suggest that there is a certain interlayer porosity (around 15\%), which causes a decrease in the density of the objects. These results are in well-agreement with the SEM images.

\begin{tabular}{cccc}
\hline & \multicolumn{3}{c}{ Density $\left(\mathbf{k g} / \mathbf{m}^{\mathbf{3}}\right)$} \\
\hline Theoretical & Extruded filament & 3D-printed objects \\
\hline ASA $+\mathbf{C}$ & 1100 & $1108 \pm 83$ & $932 \pm 43$ \\
\hline $\mathbf{A S A}+\mathbf{C}_{\mathbf{m}}$ & 898 & $861 \pm 63$ & $740 \pm 47$ \\
\hline
\end{tabular}

